\title{
Supporting Low-achieving EFL Learners: Expectations, Procedure and Significance of Remedial Sessions at a Saudi University
}

\author{
Fatimah M A Alghamdi ${ }^{1}$, Ozma Siddiqui ${ }^{1}$ \\ ${ }^{1}$ English Language Institute, King Abdulaziz University, Jeddah, Saudi Arabia \\ Correspondence: Fatimah M A Alghamdi, English language Institute, King Abdulaziz University (KAU), Jeddah, Saudi \\ Arabia.
}

Received: November 4, 2016

Accepted: November 29, $2016 \quad$ Online Published: November 29, 2016

doi:10.11114/jets.v4i12.2028

URL: http://dx.doi.org/10.11114/jets.v4i12.2028

\begin{abstract}
This study reports on and investigates an institutionalized remedial approach held by an English language institute (ELI) at a Saudi University in order to support foundation year struggling students who often achieve low grades or fail to pass a certain level of the English language program. The study utilizes semi-structured interviews to address three issues: (1) Screening for low-achieving learners; (2) Remedial sessions' procedure and significance; (3) Learners' attitudes and conduct during remedial sessions. Thematic analysis of interviews with teachers shows that time limitation and lack of logistical structure lower the effectiveness of remedial sessions in terms of numbers of supported learners and the remedial procedure itself. It was also found that class teachers' role is often lacking in this case-study. Low-achieving learners are rarely referred by their teachers, but instead come on their own to seek support. However, this optional nature of the process resulted in remedial sessions receiving learners who are self-motivated, have positive attitude, and exhibit different classroom conduct than students in the mainstream classes. Furthermore, the analysis yields other findings related to the usefulness and significance of remedial intervention. Learners were found to seek remedial support for two main reasons: supportive environment and simplified instruction. Much of this can be addressed in regular classrooms. The study concludes with other implications for remedial sessions' logistics and practices, as well as for the teaching/learning process of low-achievers.
\end{abstract}

Key words: EFL, Saudi learners, remedial classes, low-achievers, learners' motivation and attitudes, differentiated instruction

\section{Introduction}

\subsection{Context and Rationale of the Study}

Preparatory year students at an English language institute (ELI) in a Saudi university are placed in one of four levels of proficiency, which correspond to levels B, B1, A and A1 of the Common European Framework of Reference for Languages (CEFR). The preparatory year is divided into four instructional modules corresponding to these levels. ELI faculty members have observed that students who are placed in their respective levels through the placement test are suited to those levels but, as they progress through the modules, some of them begin to fall behind and are unable to cope with the curriculum. It follows that a large number of failures have become a regular occurrence at the course advance levels at the ELI.

Consequently, the ELI established the Student Academic Support Committee (SASC) as a unit especially meant to extend assistance to low-achieving students. As the committee has offered support to students over time, a number of recurring issues have been observed. Members of the committee have often commented that teachers do not encourage their students to go for remedial sessions and students visit only irregularly. The existence and function of the committee has always been questioned, at least amongst colleagues who are members of it. There appears a need to investigate the role and function of the remedial classes offered by the SASC and their significance to the low-achieving language learners. Moreover, there is a need to consider possible ways to restructure SASC procedures.

\subsection{Theoretical Background}

Intervention in second language learning (SLL) can be considered in relation to second language acquisition theories that are concerned with students' motivation (Gardner, 2001). The need for a remedial program arises from the 
awareness that students may need support at any time during their academic career. It is thought that such a support system is generally helpful to students who can seek academic support outside their class time from other tutors beside their own. Students also get an opportunity to revise the materials taught in class on an individual basis or in small groups which can help improve self-confidence and increase their sense of self-efficacy (Cheng, 2014).

Our view of this remedial approach is shaped by the construct of scaffolding, a practice that operates within the theoretical framework of social constructivism. This framework views learning as a socially mediated cognitive activity that occurs in a hypothetical zone of proximal development (Vygotsky, 1978). Remedial practices are also grounded in a number of other theoretical frameworks, including multiple intelligences (MI) and differentiated instruction (DI). From the perspective of MI, (Gardner, 1983), a lesser achieving learner is not necessarily less intelligent than another who has grasped the task more quickly, but may simply possess other abilities and need a different approach to arrive at the same achievement level. Although MI is not very well received by academics and psychologists, see Klein (1997) for a review of MI criticism, the theory in its general terms is appealing to the treatment of mixed ability learning groups. Gardner (2011) maintains that: "Human beings differ from one another and there is absolutely no reason to teach and assess all individuals in the identical way" (P. 6). Remedial intervention, particularly in the context of this study, is there to cater for students who think, or are thought to be, less able to grasp language concepts and skills in the mainstream language classes. DI can also be beneficial in remedial intervention. Weaker students who struggle with basic concepts will benefit from simplified instruction, more examples and more assistance. Differentiation is an approach to teaching that involves processing content in a way that all the students can make sense of despite their varying abilities (Tomlinson, 2001). In other words, DI provides the element of inclusiveness, or, all students learning together. A compelling argument can be made for restructuring of SASC procedures to include DI. More will be said on this, below.

\section{Review of Related Literature}

It has been argued that interventions in the learning process, such as remedial teaching, can help less successful language learners improve, not only in the target language proficiency but also in motivation and self-efficacy (Reiss, 1981; McLaughlin \& Vacha, 1992; Yang, 2010; Jadal, 2012; Cheng, 2014). In particular, low achievers can make better relationships with their peers and improve their attitude towards learning, as remedial teaching helps students "find a match between their characteristics and the school environment so that their academic and behavior demands can be met" (Cheng, 2014, p. 862). It is important that students have access to programs that meet their individual requirements and that remedial teaching has content that helps them to "consolidate basic knowledge, master their learning strategies, strengthen their confidence and increase the effectiveness of their learning" (Cheng, 2014, p. 862).

It is evident from studies carried out on students receiving remedial teaching that they had better motivational levels and were more likely to succeed academically than those who did not take advantage of such an intervention (McLaughlin \& Vacha, 1992; Yang, 2010). In particular, remedial intervention recognizes learners' individual differences and can promote motivation and self-efficacy (Cheng, 2014). Students with positive perceived self-efficacy feel more confident, are more in control of their learning and believe that they have the capability and motivation to accomplish their goals. On the other hand, students with lower perceived self-efficacy believe that they might not have the capability to succeed. Their beliefs about their ability to succeed may influence how they behave, perform, and react to difficulties.

Low-achieving learners are characterized by low perceived self-efficacy, specifically in relation to how they perceive themselves as learners (Cheng, 2014). With the aim of deepening understanding of how remedial teaching transformed low achievers' learning outcomes in English, Cheng (2014) interviewed 42 students who were involved in a remedial teaching plan, their instructor, and their class mentor, in two phases over a period of ten months. The results indicated an improvement in the students' academic and emotional perceived self-efficacy. The positive results suggested that individualized remedial teaching, direct supervision from teachers, and an appropriate support system led to better academic and emotional self-efficacy (Cheng, 2014).

Research indicates that remedial courses, when delivered appropriately, can result in significant improvement in students' language use (Al Othman \& Shuqair, 2013). However, basic skills in the use of English as a second language can only be instilled in the minds of students if they are exposed to prolonged periods of studying the language. This condition is typically lacking in remedial classes (Al Othman \& Shuqair, 2013).

A study to develop a remedial package for students in the $7^{\text {th }}$ grade (12-year-olds) was conducted by Jadal (2000) in a primary school in India. The study aimed to observe the effectiveness of the teaching materials with low achievers in particular. The students continually exhibited poor performance in all four language skills: reading, writing, speaking and listening. The low-achievers were divided into a control group and an experimental group. Thus the study sample consisted of three groups: (1) average- and above average-achieving students, (2) low-achiever control group and (3) low-achiever experimental group. The third group was taught using the remedial package. The control group and the group of average and above average students were taught using a traditional Grammar-Translation method over a period 
of 30 days. The findings indicated that instruction using the remedial package was more effective than the traditional method and helped low achievers cope better with their peers in the average and above average group. There was a significant difference in the pre-test and post-test scores of low achievers, especially with regard to speaking skills taught using the remedial package (Jadal 2000).

However, it has often been reported that remedial classes don't serve their intended purpose. The practice in some universities is to enroll students in remedial sessions prior to their starting the main course. Al Othman and Shuqair (2013) found that remedial sessions of this type were counterproductive as students felt stigmatized and de-motivated. Very few students showed significant improvement in their test results after going through the remedial sessions. This low achievement, coupled with low motivational levels, resulted in some feeling that remedial sessions should be eliminated (Al Othman \& Shuqair, 2013).

It is thought that the ineffectiveness of remedial sessions in ESL/EFL is due to the fact that students are not exposed to the practical use of the language outside the classroom setting. It was observed that students switch to their native language as soon as they step out of the classroom. Al Othman \& Shuqair (2013) argued that failure to expose students to the use of English over prolonged periods can counteract the learning which has taken place and may even erode it. Al Othman and Shuqair (2013) concluded that the remedial courses in Arab universities have been ineffective in increasing the English language skills of students, particularly in the ESL/EFL environment.

The literature on remedial support to low-achieving EFL learners is not extensive. It is also lacking much detailed investigation into the procedures, function and the effectiveness of remedial classes. Our intent is to contribute to the existing literature by examining a working model of EFL remedial support. The model has a learner-focused perspective with regards to how low-achievers are identified, how they are supported and how beneficial the remedial support is to them. This case-study qualitative enquiry into remedial practice is guided by three research questions. (1) How are low-achievers identified and referred to the SASC? (2) What is the function of remedial sessions and what is their significance to low-achievers? And (3) what are the strategies and attitudes of low-achievers who receive remedial support? By reporting on this ELI case at a Saudi university, we hope to provide insight for both researchers and educators into the role and limitations of remedial intervention for students enrolled in EFL programs; college programs, in particular.

\section{Method}

Table 1. The participants of the study

\begin{tabular}{lllllll}
\hline Code & Age group & Native-Arab & $\begin{array}{l}\text { Years } \\
\text { experience } \\
\text { teaching EFL }\end{array}$ & $\begin{array}{l}\text { Years } \\
\text { experience } \\
\text { the ELI }\end{array}$ & $\begin{array}{l}\text { of } \\
\text { at }\end{array}$ & $\begin{array}{l}\text { Years } \\
\text { experience } \\
\text { the SASC }\end{array}$ \\
\hline Participant M & $45-55$ & Yes & $15+$ & 18 & 3 \\
Participant S & $45-55$ & No & $20+$ & 8 & 4 \\
Participant F & $35-44$ & Yes & $10+$ & 3 & 2 \\
Participant E & $25-34$ & No & $5+$ & 2 & 1 \\
\hline
\end{tabular}

Table 2. Interview questions and prompts

\begin{tabular}{|c|c|}
\hline Theme & Questions \\
\hline Screening for low-achievers & $\begin{array}{l}\text { (1) How do you think students are judged to be low-achievers? } \\
\text { (2) Who refers them to the SASC? }\end{array}$ \\
\hline $\begin{array}{l}\text { Remedial teaching function, procedure and } \\
\text { significance }\end{array}$ & (3) What are the students' expectations from the remedial sessions? \\
\hline & $\begin{array}{l}\text { What does a remedial session look like and how does the process go? } \\
\text { Material } \\
\text { Approach } \\
\text { Interaction } \\
\text { Number of students } \\
\text { Duration }\end{array}$ \\
\hline Student's attitudes and conduct & $\begin{array}{l}\text { Do learners behave differently in the remedial sessions than in the } \\
\text { regular classes? }\end{array}$ \\
\hline
\end{tabular}

Data for this study was collected from four members of the ELI SASC during the last of the four academic modules in the preparatory year. The SASC members all teach at the ELI, and their total teaching experience (at the ELI and elsewhere) varies between 5 and 20 years. They are all near-native English speakers or English second-language speakers. Two of the teachers are non-Arab, and two are native Arab. The data collection process took place during the second semester of the academic year (March-May 2016). The students we refer to are all female preparatory year students who had enrolled in the university in August of the previous year, and thus had been studying English for the preceding 8 months. Table 1 shows some information about the SASC members who participated in this study (pseudonyms are used throughout). 
Semi-structured interviews were conducted with the four SASC members individually, each lasting between 12 and 18 minutes. Five main questions guided the interviews with prompts sometimes added to elicit more information. Table 2 below illustrates how the five questions relate to the themes of this qualitative inquiry.

\section{Data and Analysis}

The four interviews with SASC members were transcribed, then analyzed and coded following a thematic analysis procedures by identifying recurrent themes (Joffe and Yardley, 2003). This was guided by the three main themes of the research questions: (1) the set-up of the remedial sessions (including screening for low achievers and how they get to SASC), (2) the function of the sessions (including material, instruction and interaction, etc.) and their significance for the low-achievers, and (3) the attitudes and behavior of the remedial session clients. However, subthemes and categories emerged from the conversations.

\subsection{Screening for and Referral of Low-achieving Students}

The SASC tutors who participated in this study all agreed that in spite of the institutional protocols that require the teachers to refer low-achieving students to the committee, very few students come to the remedial classes through teachers' referrals. The majority of students come to seek help individually or with the encouragement of their peers. Moreover, our participants reported that the students may be reluctant to attend remedial classes because they either fear upsetting their regular class teachers by seeking help from a different teacher, or they need encouragement to go and seek help.

I feel the teachers are not actively engaged in the objectives of the SASC. They think that when they're sending their students ... it is as if we are judging their performance as teachers, so they never send them. (Participant F)

The participants were encouraged to talk about how they recognize low-achieving students from their point of view as teachers. The responses of the four participating teachers varied in the way they spot weaker students but they all had one thing in common: it is not difficult, and it does not take long to spot low-achieving students. Participant M neither leaves it to chance nor to the first assessment occasion to figure out who the weaker students are:

A way to spot weak students is to let them take turns in answering exercises. I let them answer voluntarily by raising their hands, but I also ensure so that each one gets a chance to answer. I can detect a weak student from the way she answers, her hesitation and the way she pronounces words; she usually isn't confident and seems unsure of herself. However, everyone has to participate in the classroom activities.

Participant F and Participant E, on the other hand, choose to delay judging the level of the students. Participant F said "I never judge at the beginning, but through experience". Similarly, Participant E noted that "the first session is quite misleading because I see students who seem to be weak but they gain pace later on in the course," and that one needs to "monitor their [the students'] work during class and observe quizzes and quiz results, which would definitely determine learners' problems."

Participant $\mathrm{S}$ believes it is the teacher who has the main role in identifying low-achievers and referring them, explaining that teachers can judge students through assessment, formal and informal, as well as through observing them during class time: ".. and to notice that certain students are not able to keep up with their peers."

Participant $\mathrm{S}$ noted that low-achieving students can be identified from their interaction and behavior in class, and illustrated a behavioral profile of low-achievers that is similar to the one depicted by Participant M: "They are hesitant and do not participate in activities." The following table shows the participants' reports on the traits and behavior of low-achieving students in regular classes.

Table 3. Reported traits and behavior of low-achieving students in regular classes

\begin{tabular}{ll}
\hline & $\begin{array}{l}\text { Traits and behavior of low-achieving students in regular } \\
\text { classrooms }\end{array}$ \\
\hline Participant M & - Hesitant. \\
& - Have problems with pronunciation. \\
Participant S & - Lack self-confidence. \\
& - Not able to keep up with their peers. \\
& - Look at their peers' work instead of doing their own. \\
& - Don't participate in groups. \\
Participant F & - Will let the other person dominate when working in pairs. \\
& - Can't voice their opinion in class. \\
Participant E & - Big discrepancy between them and the rest of the group. \\
& - Not able to follow the class. \\
& - Unwilling to participate.
\end{tabular}




\subsection{The Function and Procedure of Remedial Sessions and Their Significance to Learners}

For most students, remedial classes are mainly seen as a preventive measure to stop them from failing the courses. Participant S reported: "They're just hoping that we will be able to help them enough to pass." The low-achieving learners, according to Participant M, "expect that the remedial classes are the solution to their problems ... to understand what they couldn't understand in class due to several factors".

Concerning the exact kind of help the students need, it includes explaining textbook material they couldn't understand. They often ask a lot of questions regarding concepts, form and function of grammar, vocabulary practice, reading materials and revision sheets.

They ask a lot of questions ... and they keep asking and ... I'd explain something and they ask why this, can you repeat, then I repeat and they ask again. They expect to leave the remedial class with much more information and a better idea about the areas they didn't understand in class. They place their hope in the remedial session teacher. (Participant M)

Similarly, Participant F, Participant S and Participant E commented that remedial sessions' clients expect coverage of the same text material covered by class teachers. Participant F said: "They expect me to cover every single unit from unit one to the last unit, but this is difficult owing to time constraints." Other participants are aware of the significance of textbook material to the students:

Usually it's material that they have not understood in class they would like us to go over it again, they are hoping they can get some translation in Arabic. We have students who constantly speak in Arabic, but somehow they navigate through the English we use on a one to one basis. (Participant S)

I think they generally.. they want like a pill. A condensed, quick course to revise, but a lot of students come who actually ... they didn't attend the classes for some reason, so they want to just catch up with ... with their class. So they come and say, ok teacher I want to do units from one to four. And they don't have any specific skill they want to work on they just wanna go over the units, so that's the most common in my case. I have this kind of students who ... give me anything in those four units or five units, the units they have missed. (Participant E)

Participant F, however, is convinced that the affective drive is what makes the students come to remedial class: “I think these students are introvert students, they might be weak but I think they are mostly introvert. But when they come, we offer very individualized teaching, so that's why they are open to us." Likewise Participant M has also highlighted the sense of security remedial classes clients feel simply because they are with a group of people who share similar inadequacies.

Procedures of the remedial sessions, including number of students, duration of the session and the material and approach varies amongst the four participants of the study. Participant M believes in breaking up the grammar items into their individual parts and delivers the grammar rules explicitly.

Students mostly seek help in grammar so I break the grammar items into small chunks which can be easily assimilated by the learner. For instance, I may start with explaining the rule for 'some' and 'any', ask about their function, their form and place in the grammatical unit of a sentence (what do you think follows 'some'? 'Is it only nouns? Which ones?') (Participant M)

Participant $\mathrm{M}$ also believes that relating students' own life's experiences to the grammar forms and functions results in effective learning. Participant F uses Arabic judiciously to explain items which would otherwise be obscure. However, Participant $F$ noted that the students have a better understanding of English grammar than Arabic grammar.

I could also talk about count and non-count nouns and give real life examples looking for experiential responses such as a real life situation where they are likely to use the grammar item such as a department store. What language can she use if needs to buy a pair of shoes, for example. I may need to point out to her whether the noun 'shoes' is singular or plural. I also make judicious use of Arabic particularly if there are comparisons that can be made such as infinitives and gerunds which are very similar in the Arabic language. Curiously, they usually have a better understanding of the rules of English grammar than Arabic which works in their favor. (Participant F)

Participant S outlines the process of the remedial session which typically starts with questions posed by the tutor about the area of difficulty. The tutor gets on with the task of helping the students immediately, either from the text book, resources brought by the student or by providing resources of her own.

The groups are not very large; each tutor can receive up to 4-5 students per week or 2-3 per session. The class normally starts with asking the students where the problem lies. If it is in the students' course book, they will point it out to us. Sometimes they carry extra resources given by their teacher which they would like us to help 
out with. As we normally have only an hour and the main teaching is done by their section teachers, we encourage them to identify the areas they need support in. Students typically ask us for worksheets and many of us are equipped with both hard and soft copies, related videos which we can show them using the classroom projectors. (Participant $\mathrm{S}$ )

Participant $\mathrm{S}$ notes that students are more confident about asking questions in these sessions and more actively involved in the learning process which is evidenced by their taking notes and giving feedback.

The nature of the interaction involves the tutor asking questions, in the main, and students pointing out the areas of difficulty. They usually write down notes which they take away with them and are also good at giving feedback. Moreover, they are more confident about asking questions and receiving help in these sessions. (Participant S)

Commenting on her teaching strategies, Participant S mentions taking advantage of technology to in these remedial sessions, noting that students generally experience interference of the L1 while learning the L2 particularly in teaching language items which may not exist in the L1.

... there may be strategies which students employ the most visible, such as translation from the English to the Arabic for any new vocabulary, whether it is stand alone or contextual. I often use Google translate owing to its being convenient and for instantaneous understanding on the part of the student. It is a fact that these students need translation but although it is not obvious, we can observe the student negotiating the translation to employ it appropriately to the material at hand and make sense of what we are trying to teach them from the text book. There is certainly considerable L1 interference as they try to negotiate the L2. (Participant S)

Participant $\mathrm{S}$ is aware, however, that not all English structures could be taught in reference to similar Arabic structures. She recognizes that absence of similar forms poses difficulty in getting the English forms through to the learners.

Certain structures which do not occur in the Arabic, such as the present perfect or idiomatic phrases, can pose challenges for both the tutor and the student. While the Present Perfect can be taught using timelines and giving examples, as well as the instructional videos, there is often an overlap in the function conveyed by the Simple Past tense. It is more difficult with idiomatic phrases, however. (Participant S)

Participant F runs the remedial sessions slightly differently, claiming that students expect remedial teachers to cover every single unit starting from unit one.

Sometimes I can receive up to six students. I start with asking them about their level and what they expect to get help with. Sometimes, they simply wish to share their insecurities or seek emotional support. Often one method may work for one student but not for the other. So I try to adapt activities to match their level and objectives. I usually have my own resources and varied worksheets.

Participant E's method is to do a quick needs analysis which provides a departure point for the remedial session. Participant E teaches through testing and then re-teaches using interactive materials.

I usually do a quick needs analysis to see what they need, particularly if they don't have a referral form from their section teacher. My method is to Test-Teach-Test so I give them a quiz or a task to complete. If they have any problems, I go over the task and I use a lot of interactive material like Socrative which is easy to use and implement. Students can do it on their mobile but I also display it on the wall so they can see their mistakes. (Participant E)

The duration of the sessions and the number of students in each session is usually not planned but depends on how many students come and how long they are prepared to stay.

\subsection{Students' Conduct and Attitude during Remedial Sessions}

There is a stark contrast in the behavior of low achieving students in remedial sessions as opposed to ordinary classes. The participants have all noted that low-achieving students are more attentive and have a better attitude in remedial sessions. Participant M and Participant F, in particular repeatedly stressed how relaxed and at ease the clients of the remedial sessions are: "They are at ease, more focused and interested in learning" (Participant M). "They are certainly more involved and there is a very positive rapport. They are open to discussion and willingly talk about their low self-esteem in the regular classes as well as their de-motivation" (Participant F).

They concentrate and they are more focused. They are not afraid to ask questions which they would not ask in a class where they would typically be submissive or subdued. They are certainly happier in the remedial sessions than in their original classroom. (Participant $\mathrm{S}$ )

This high level of comfort experienced by the students in the remedial sessions certainly reflects in their increased 
confidence as well as their motivation. Participant F attributed this to the teachers' approach: "I'm open to them, I smile, I speak in Arabic. I think it important that we speak Arabic. Sometimes they come to us because we speak in Arabic." Likewise, Participant S reported on the confidence remedial sessions' clients have, but attributed this in part to the support low-achieving learners get from being in groups: "Sometimes we have a group of students who come as friends. Then there's a better level of confidence and better level of rapport."

One of the reported advantages of remedial classes is that students feel they are in a similar situation as their peers, and that the very actions that would annoy their classmates in a regular class are the ones preferred in a remedial class, such as asking the teacher to repeat. "They are relaxed and not embarrassed to ask. They feel at ease. They know they are in a session where they all came to understand. They feel that they will benefit the others by asking questions" (Participant M).

Related to positive attitude is the gratitude the students feel towards remedial session instructors. Almost all the participants commented on how polite and grateful remedial classes' clients are. They always thank the teachers and show gratitude. Participant F reported:

Students are very grateful to be provided with this chance of being in close interaction with a tutor. They thank me in person and feel happy to call or text me. They are very polite and continually appreciative for what we can do for them. Where regular students overlook acknowledging me outside the classroom, these students never fail to greet me.

\section{Discussion}

One of the objectives of this inquiry is to provide a description and a critique of an existing remedial intervention model. By doing so, the authors aim to inform educationalists in the EFL community about both the potential for benefit and the inadequacies of such interventions, as well as their significance to learners. Data show that the particular context of the present study may differ from contexts of remedial classes elsewhere. The fact that one four-level curriculum is taught to all the students at this ELI, that students are administered unified exams, and that these exams are not known to teachers, are all factors that impose restrictions on what is taught and the duration of teaching in remedial sessions and how the content is taught. The majority of the students come with the single aim of understanding what they could not grasp in the classroom, in order to pass the summative tests. In most cases the teachers are compelled to repeat the textbook entries or go over the exercises that were already tackled in class. These practices leave little room for proper remedial instruction where a teacher would be promoting a comprehensive language learning experience. Moreover, even with this goal in mind, i.e. helping the learners to do well in the exams, SASC members are hindered by their inability to anticipate exam questions.

The original procedure of the remedial sessions was to have the teachers refer low-achieving students to the SASC via referral forms, which detail what the student needed help with. However, as our participants have come to know, very few students are referred by their class teachers. The students approach the SASC services on their own initiative. They come to seek help mostly with the course material which they have either missed due to absence, or been unable to grasp during the regular lesson. In this sense, the remedial sessions' function seems to address an essential gap in the teaching/learning practices in this EFL context, namely differentiated instruction (i.e. classroom instruction that is appropriate for all). In order for classroom instruction to be effective it has to be stratified to cater to different abilities, intelligences and learning styles. This is probably what the SASC members try to do within the limitations of time and resources. They do this by simplifying material, repeating input, and using Arabic to explain concepts of the English language.

Another significant issue reported by the participants is that the students come to remedial classes to be with peers who share similar inadequacies and concerns. In other words, students seek out the remedial classes for a supportive environment, where input is delivered at a significantly slower pace and repeated as many times as needed without fear of boring more proficient classmates.

It should be a cause for alarm to the educationalists of this particular academic community to note that students are more relaxed and motivated when attending remedial sessions than in regular classrooms. The reported variation in the conduct of low-achieving students in remedial and regular sessions reflects a number of things. It is obvious that the students do not feel safe in regular classes. They are intimidated both by their lack of self-efficacy and by the fact that other students are more able than they are. By coming to the remedial sessions, low-achieving students seek an empathetic teacher and a comfort zone that is shared with other students in a similar predicament.

Another important issue revealed in the data relates to the effectiveness of remedial classes and the measurability of their outcomes. The effectiveness of remedial sessions in the context of this study cannot be measured, as SASC does not keep records of what happens to its clients afterwards, partly because SASC members do not have access to students' 
assessment results. In addition, there is no way to determine how much credit the committee can take in the students' success or, alternatively, how far it may be responsible for their failure. One participant has particularly expressed concern about the immeasurability of the outcome of remedial classes: "There is no real measure that they've done any learning but the fact that she's satisfied and goes away with a smile, and will probably return is all the encouragement I have. It tells we've been ok with that" (Participant S).

Moreover, our participants complained of the short contact time with remedial sessions' clients. In other words, remedial sessions are ineffective because the English language skills acquired in the available time are short-lived. Chen, et al. (2013) explained that tutors tend to focus on having their students pass their test instead of equipping them with comprehensive language skills.

\section{Implications}

The findings of this study have implications for both regular and remedial language teaching. Regular language classes can satisfy most of students' demands that bring students to remedial classes. We found that the significant features of remedial classes, i.e. affective support, slower pace and simplified material, can be addressed in well-planned language classes, by well-informed and trained language teachers.

In addition, this study has implications for a systematic remedial program where students perceived as 'weak' may be taken in hand from the beginning and their progress monitored throughout the levels. Efforts made to maintain students' attendance in the remedial course, across all the instructional levels, through keeping in direct contact with the students themselves, will ensure sustained academic support for such students as need it. Such efforts would upgrade remedial teaching in this particular context from the category of desk-side coaching to an opportunity to develop and explore learning in a supportive environment.

\section{Conclusions}

Our case study investigation of remedial support has highlighted three significant issues in remedial intervention that, once addressed, will probably increase its effectiveness with regard to students. These are (1) the need to systematically identify low-achievers and monitor their progress, (2) the significance of simplification and differentiation of material and instruction and (3) the impact that affective support has on learners' motivation and attitude.

This study drew our attention to the need to incorporate screening and follow-up measures for low-achieving learners into the operation of the ELI. The process of screening for low-achievers in this particular context is alarmingly unsystematic and lacks standardized measures. Class teachers seem to be reluctant to send their students to get help. This lack of a uniform model of remedial intervention has probably led to many students in need of support being left behind and thus to a case of unequal learning opportunity. The implementation of an academic support system needs more defined logistics and reinforcement measures, the most essential of which is pre-assessment and continued assessment measures, which in turn need to address instructional goals, yet at the same time be independent from the final exam focus.

Remedial teaching in this case study was found to operate within a model where DI is playing an instrumental role. Differentiation was achieved through three main strategies: repetition, use of the Arabic language and use of simpler learning material. There remains a need to invest time and efforts in designing proper remedial material. DI, as well as other theoretical models that account for mixed ability classrooms, can inform the designing and delivering of language learning material. There is also a need to reassess the role of classroom teachers in dealing with learners of different language learning abilities and skills. Further research on the significance of remedial intervention will benefit from investigating teachers' awareness of and readiness to practicing DI.

Academic support as a process that gets language skills and concepts through to students is probably only one aspect of the remedial process; a process that yields equally important byproducts. These include motivation and a secure environment. The students come to the remedial sessions in search of reassurance and affective support and to avoid embarrassment when they ask for more explanation. So if these affective motivational factors can be addressed in regular classes, then the efficiency of those classes may increase. A positive change can be promoted by raising, through training, teachers' awareness of the affective side of the EFL learning process and by taking measures to address learners' fears and insecurities.

The particular context of remedial sessions under study has contributed to the emergence of certain practices, such as the focus on grammar drilling and translation. Also, students' ultimate goal of passing exams has not only shaped the content and pace of the remedial lessons, so as to make them less of an opportunity for effective language development, but also has caused a feeling of helplessness on the part of remedial class teachers. They think that since they do not know content of the final exam they are unable to help the low-achieving students in the optimal way. Moreover, students' efforts at improving their English for the sole purpose of passing the final exam has ironically led to the 
students missing class sessions themselves, as some of them have felt they could better use the time for private study to improve their chances of passing exams.

Finally, anyone working in language education, the goal of which is to facilitate the acquisition of language as a medium of communication and knowledge exchange, would be alarmed at the sheer magnitude of focus on passing summative exams. So, although passing the tests is a condition of success and progress in the college preparatory year, this goal needs to be appropriately distanced from remedial support. It is hoped that perhaps a systematic program of student support, one based on needs analysis and reassessment, will foster development of profound skills and knowledge that will eventually 'trickle down' in ways that help the students pass their exams.

\section{Acknowledgement}

We would like to thank Dr. Susan Duncan and the anonymous reviewer for their very useful comments on earlier versions of this paper. Any errors that remain are our own.

\section{References}

Al Othman, F. H., \& Shuqair, K. M. (2013). Effectiveness of the remedial courses on improving EFL/ESL students' performance at university level in the Arab world. International Journal of Higher Education, 2(3), 132-138. https://doi.org/10.5430/ijhe.v2n3p132

Cheng, C. M. (2014). Individual differences: How remedial teaching transforms low-achievers when learning English. Journal of Modern Education Review, 4(11), 859-877. https://doi.org/10.15341/jmer(2155-7993)/11.04.2014/001

Gardner R. (2001). Integrative motivation and second language acquisition. In Z. Dörnyei \& R. Schmidt (Eds.), Motivation and Language Acquisition, Honolulu, HI: University of Hawaii Press, 1-19.

Gardner, H. (1983). Frames of Mind: The Theory of Multiple Intelligences. New York: Basic Books.

Gardner, H. (2011). The theory of multiple intelligences: As psychology, as education, as social science. Address delivered at José Cela University on October, 29, 2011. Retrieved from https://howardgardner01.files.wordpress.com/2012/06/473-madrid-oct-22-2011.pdf

Jadal M. M. (2012). Developing skills of English through remedial package by low achievers at primary level, Journal of Arts and Culture, 3(2), 118-122.

Joffe, H., \& Yardley, L. (2004). 4. Content and thematic analysis. Research Methods for Clinical and Health Psychology. California: Sage, 56-68.

Klein, P.D. (1997). Multiplying the problem of intelligence by eight: A critique of Gardner's theory. Canadian Journal of Education, 22(4), 377-394. https://doi.org/10.2307/1585790

McLaughlin, T. F., \& Vacha, E. F. (1992). The at-risk student: A proposal for action. Journal of Instructional Psychology, 19, 66-68.

Reiss, M. A. (1981). Helping the unsuccessful language learner. The Modern Language Journal,65(2), 121-128. https://doi.org/10.1111/j.1540-4781.1981.tb00960.x

Tomlinson, C. A. (2001). How to Differentiate Instruction in Mixed-ability Classrooms. Upper Saddle River, NJ: Merrill Prentice Hall.

Vygotsky, L. (1978). Interaction between learning and development (M. Lopez-Morillas, Trans.). Chapter 6 in M. Cole, V. John-Steiner, S. Scribner, \& E. Souberman (Eds.), Mind in Society: The Development of Higher Psychological Processes (pp. 79-91). Cambridge, MA: Harvard University Press.

Yang Y. (2010). Developing a reciprocal teaching/learning system for college remedial reading instruction. Computer \& Education, 55, 1193-1201. https://doi.org/10.1016/j.compedu.2010.05.016

This work is licensed under a Creative Commons Attribution 3.0 License. 